\title{
Antimicrobial Susceptibility Patterns of Coryneform Bacteria Isolated from Semen
}

\author{
Silver Türk ${ }^{1}$, Margus Punab ${ }^{2}$ and Reet Mändar ${ }^{*}, 1$ \\ ${ }^{1}$ Department of Microbiology, University of Tartu, Ravila 19, 50411 Tartu, Estonia \\ ${ }^{2}$ Andrology Centre, Tartu University Hospital, Puusepa 1a, 50406 Tartu, Estonia
}

\begin{abstract}
Background: The susceptibility of coryneform bacteria has been studied mostly in invasive pathogens, less data are available concerning the mucosal or physiological fluid strains. At the same time they can serve as the source of various infections, besides the invasive infections also the local ones, for example, coryneforms of male genital tract have been associated with inflammatory prostatitis.
\end{abstract}

Material and Methods: A total of 62 coryneform isolates from human semen were tested for susceptibility to eight antimicrobial agents using the E test method.

Results: All strains were susceptible to ampicillin-sulbactam and only a few were resistant to penicillin G and TMP/SMX while nearly one third of strains were resistant or intermediate to doxycycline (35\%) and norfloxacin (29\%), and more than half to clindamycin (63\%), nitrofurantoin (62\%) and erythromycin (53\%). The strains showing resistance to at least 3 antimicrobials belonged to Corynebacterium group F1, Corynebacterium seminale and Cellulomonas/Microbacterium sp. A distinct co-occurring macrolide and lincosamine resistance pattern was common.

Conclusion: Ampicillin-sulbactam, penicillin G and TMP/SMX revealed the highest activity against coryneforms isolated from semen that were frequently resistant or intermediate to several other antimicrobials. Norfloxacin revealed only moderate activity against prostatitis-associated Corynebacterium group $\mathrm{G}$.

Keywords: Antimicrobial susceptibility, Corynebacterium, coryneform, semen, prostatitis.

\section{INTRODUCTION}

Coryneform bacteria are common inhabitants of the mucous membranes and skin. This colonization can lead to infection, especially in neutropenic patients and in patients undergoing surgical manipulations but also in immunocompetent subjects. In addition to the invasive infections these bacteria have been associated also with the local infections, for example, inflammatory prostatitis [1-4].

It is believed that the pathogenicity of coryneform bacteria has been underestimated and often underappreciated, despite increasing numbers of reports associating corynebacteria with human infections. Therefore a renewed interest in Corynebacterium and similar species has emerged during the last decades among clinicians and microbiologists alike [5, 6]. At the same time, there are few reports about their antimicrobial susceptibility. These studies have frequently indicated high resistance of coryneform bacteria to antibiotics $[6$, 7], and it is also proposed that corynebacteria can be the reservoir of drug resistance genes [8]. The susceptibility pattern of coryneform species has been researched mostly in association with emergence of multiresistant nosocomial pathogens, less data are available concerning the mucosal or physiological fluid strains.

*Address correspondence to this author at the Department of Microbiology, University of Tartu, Ravila 19, 50411 Tartu, Estonia; Tel: +372 7374 178; Fax: +372 7374 172; E-mail: Reet.Mandar@ut.ee
We evaluated the antimicrobial susceptibility of different coryneform species isolated from human semen.

\section{MATERIAL AND METHODS}

\section{Study Group}

The study was carried out between September 2003 and May 2005 at Tartu University Hospital. The study group included 109 men, of them 37 men were the participants of the prospective study of the etiopathogenesis of chronic prostatitis, and 72 men were the participants of the prospective study Environment and Reproductive Health (EU $6^{\text {th }}$ FP project QLRT2001-02911). In 50 out of 109 men, leukocytospermia was found, therefore, NIH IIIa category prostatitis (20 men) or NIH IV category prostatitis (30 men) was diagnosed in them according to the NIH Classification of the Prostatitis Syndromes as described [1]. The remaining 59 men had neither pelvic pain/discomfort complaints nor leukocytospermia; therefore, they served as a control group. The mean age in prostatitis patients was 28.5 (SE \pm 0.62$)$ years and $20.0( \pm 1.32)$ years in controls. All subjects were at least 18 years old. None of the men had received antimicrobial therapy within 3 months. Participation in the study was voluntary. Informed consent was obtained from the patients. The studies were approved by the Ethics Review Committee on Human Research of the University of Tartu.

\section{Samples}

Semen samples were collected by patients after they washed their glans penis with regular soap and water, and 
urinated. The samples were obtained by masturbation and were ejaculated into a sterile collection tube in a private room near laboratories. After ejaculation, the semen was incubated at $37^{\circ} \mathrm{C}$ for 25 to 45 minutes for liquefaction.

\section{Isolation and Identification of Coryneform Bacteria}

The samples were cultured quantitatively to detect anaerobic, microaerophilic and aerobic bacteria within 1 hour from collection. Freshly prepared blood agar and chocolate agar, Wilkins-Chalgren medium (Oxoid, Unipath, Basingstoke, UK) supplemented with 5\% horse blood, WilkinsChalgren medium supplemented with $5 \%$ horse blood and GN supplement (Oxoid), MRS agar (Oxoid) and Gardnerella vaginalis-selective agar (Oxoid) were used. Aerobic (blood agar) and microaerobic (chocolate agar, MRS agar and Gardnerella vaginalis-selective agar in $10 \%$ $\mathrm{CO}_{2}$ atmosphere) cultures were incubated at $37^{\circ} \mathrm{C}$ for $1-3$ days, anaerobic cultures (Wilkins-Chalgren media in an anaerobic glove box) for 3-5 days.

Colonies with different morphology were Gram stained and examined microscopically. Primary identification of coryneform bacteria was performed by Gram stain morphology and catalase test. Coryneform bacteria were found from blood agar, chocolate agar, Wilkins-Chalgren medium and Gardnerella vaginalis selective agar. They were identified using the API Coryne biochemical identification system (bioMérieux, France) according to manufacturer's instructions with an exception of Corynebacterium seminale strains that were identified with beta-glucuronidase test on blood agar with MUG supplement (Oxoid), visualizing a positive reaction as a fluorescence near colonies under $254 \mathrm{~nm}$ ultraviolet light.

\section{Bacterial Isolates}

Coryneform bacteria were found in semen of 38 men with inflammatory prostatitis and 49 controls; altogether 148 coryneform strains were isolated from semen samples as described elsewhere [1]. Subsequently, 62 randomly selected isolates (36 from inflammatory prostatitis patients and 26 from controls) were included into susceptibility testing: Corynebacterium seminale (29 strains; of them 17 from prostatitis patients and 12 from controls), Corynebacterium group G $(8 ; 7 / 1)$, C. jeikeium $(7 ; 2 / 5)$, C. striatum $(4 ; 4 / 0)$, Dermabacter hominis (4; 0/4), Cellulomonas/Microbacterium sp. (4; 2/2), Corynebacterium group F1 $(2 ; 2 / 0)$, Brevibacterium sp. (1;0/1), Turicella otitidis (1;0/1), Arthrobacter sp. $(1 ; 1 / 0)$, and C. mucifaciens $(1 ; 1 / 0)$.

\section{Susceptibility Testing}

The E-test susceptibility testing method was chosen since it has shown a good correlation of MICs with both broth microdilution and agar dilution in tests with Corynebacterium spp. [7]. The E test strips (AB Biodisk) on cation adjusted Mueller-Hinton agar (Oxoid) supplemented with 5\% of blood were used as described elsewhere [9] and following manufacturer's recommendations. Minimal inhibitory concentrations (MICs) for 8 antibacterial agents were determined. CLSI (Clinical and Laboratory Standards Institute, formerly NCCLS) interpretive criteria for corynebacteria were used for penicillin $\mathrm{G}$, trimethoprim-sulfamethoxazole (TMP/SMX), doxycycline, erythromycin and clindamycin [10]. Because no CLSI interpretive criteria for corynebacteria exist as concerns ampicillin-sulbactam, norfloxacin and nitrofurantoin, breakpoints for staphylococci were used for these antibiotics as suggested elsewhere [5, 11, 12]. The strains were considered susceptible (resistant) if their MICs were as follows: penicillin $\mathrm{G} \leq 1 \quad(\geq 4) \mu \mathrm{g} / \mathrm{mL}$, ampicillinsulbactam $\leq 8 / 4(\geq 32 / 16) \mu \mathrm{g} / \mathrm{mL}, \mathrm{TMP} / \mathrm{SMX} \leq 2 / 38(\geq 4 / 76)$ $\mu \mathrm{g} / \mathrm{mL}$, doxycycline $\leq 4 \quad(\geq 16) \mu \mathrm{g} / \mathrm{mL}$, erythromycin $\leq 0.5$ $(\geq 2) \mu \mathrm{g} / \mathrm{mL}$, clindamycin $\leq 0.5(\geq 4) \mu \mathrm{g} / \mathrm{mL}$, norfloxacin $\leq 4$ $(\geq 16) \mu \mathrm{g} / \mathrm{mL}$ and nitrofurantoin $\leq 32(\geq 128) \mu \mathrm{g} / \mathrm{mL}$.

\section{RESULTS}

The minimal inhibitory concentrations and numbers of non-susceptible (resistant plus intermediate) strains are presented in Table $\mathbf{1}$.

All tested strains were susceptible to ampicillinsulbactam, one strain was resistant and 3 strains intermediate to penicillin G. Single strains were resistant to TMP/SMX $(5 \%)$ and doxycycline $(6 \%)$ but intermediate resistance was common to the latter (29\%). More than half of coryneforms were resistant or intermediate to clindamycin (63\%), nitrofurantoin $(62 \%)$ and erythromycin $(53 \%)$, somewhat less strains to norfloxacin (29\%). Similar susceptibility pattern was characteristic to the most common species, $C$. seminale, most of its strains were resistant or intermediate to clindamycin, erythromycin, doxycycline and nitrofurantoin.

One Cellulomonas/Microbacterium sp. strain was resistant to 4 (erythromycin, clindamycin, penicillin $\mathrm{G}$ and nitrofurantoin), one Corynebacterium group F1 strain to 3 (erythromycin, clindamycin, doxycycline) and $3 \mathrm{C}$. seminale strains to 3 antimicrobials (erythromycin and clindamycin combined with norfloxacin, nitrofurantoin or TMP-SMX). In addition, 20 strains (12 C. seminale, 4 Corynebacterium group G, 2 D. hominis, 1 C. striatum, and 1 Cellulomonas/Microbacterium sp.) were resistant to 2 antimicrobials. The susceptibility of the strains originating from inflammatory prostatitis patients and those of controls were compared (data not shown) and no significant differences were found.

Susceptibility pattern of Corynebacterium group $G$ is given in Fig. (1), indicating that all investigated strains of this group were susceptible to ampicillin-sulbactam and penicillin G, majority of strains were susceptible to TMP/SMX and doxycycline, half of strains to erythromycin and norfloxacin, quarter of strains to clindamycin and none to nitrofurantoin.

\section{DISCUSSION}

Since our strains originated from the male genital tract we have tested their susceptibility mainly to antibiotics commonly used in andrological practice. According to our previous study [1], two coryneforms - rather common Corynebacterium group $\mathrm{G}$ and rather uncommon genus Arthrobacter - were found to be associated with prostatitis. Of them, Arthrobacter resisted to nitrofurantoin and clindamycin but Corynebacterium group $\mathrm{G}$ showed relatively high resistance to many antibacterial agents. The latter microor- 
Table 1. Susceptibility of Coryneform Bacteria Originating from Human Semen to 8 Antimicrobial Agents

\begin{tabular}{|c|c|c|c|c|c|}
\hline \multirow{2}{*}{ Organism (No. of Isolates) } & \multirow{2}{*}{ Antimicrobial Agent } & \multicolumn{3}{|c|}{$\operatorname{MIC}(\mu \mathrm{g} / \mathrm{mL})$} & \multirow{2}{*}{$\begin{array}{c}\text { Number }(\%) \text { of } \\
\text { Non-Susceptible Strains** }\end{array}$} \\
\hline & & Range & $50 \% *$ & $90 \% *$ & \\
\hline \multirow{8}{*}{ Corynebacterium seminale (29) } & $\mathrm{TMP} / \mathrm{SMX} * * *$ & $<0.0002 \ldots>32$ & 0.38 & 1 & $1(3 \%)$ \\
\hline & Doxycycline & $0.094 \ldots 24$ & 6 & 12 & $18(62 \%)$ \\
\hline & Erythromycin & $<0.015 \ldots>256$ & 1.5 & 32 & $18(62 \%)$ \\
\hline & Penicillin G & $0.003 \ldots 1.5$ & 0.023 & 0.25 & $1(3 \%)$ \\
\hline & Ampicillin-sulbactam & $<0.016 \ldots 4$ & 0.023 & 0.38 & $0(0 \%)$ \\
\hline & Nitrofurantoin & $1.5 \ldots>512$ & 48 & 96 & $16(55 \%)$ \\
\hline & Norfloxacin & $0.064 \ldots 24$ & 1.5 & 12 & $6(21 \%)$ \\
\hline & Clindamycin & $<0.016 \ldots>256$ & $>256$ & $>256$ & $18(62 \%)$ \\
\hline \multirow{8}{*}{ Corynebacterium group G (8) } & TMP/SMX & $0.25 \ldots . .50$ & 0.44 & 50 & $1(13 \%)$ \\
\hline & Doxycycline & $0.125 \ldots 24$ & 0.38 & 24 & $1(13 \%)$ \\
\hline & Erythromycin & $0.023 \ldots 16$ & 0.625 & 16 & $4(50 \%)$ \\
\hline & Penicillin G & $0.064 \ldots 0.5$ & 0.172 & 0.5 & $0(0 \%)$ \\
\hline & Ampicillin-sulbactam & $0.09 \ldots 0.5$ & 0.19 & 0.5 & $0(0 \%)$ \\
\hline & Nitrofurantoin & $96 \ldots>256$ & 112 & $>256$ & $8(100 \%)$ \\
\hline & Norfloxacin & $0.19 \ldots 12$ & 1 & 12 & $4(50 \%)$ \\
\hline & Clindamycin & $0.38 \ldots 3$ & 1.5 & 3 & $6(75 \%)$ \\
\hline \multirow{8}{*}{ C. jeikeium (7) } & TMP/SMX & $0.125 \ldots 2$ & 0.75 & & $0(0 \%)$ \\
\hline & Doxycycline & $0.19 \ldots 1$ & 0.25 & & $0(0 \%)$ \\
\hline & Erythromycin & $0 \ldots 12$ & 0.047 & & $2(29 \%)$ \\
\hline & Penicillin G & $0.047 \ldots 1.5$ & 0.19 & & $1(14 \%)$ \\
\hline & Ampicillin-sulbactam & $0.064 \ldots 1.5$ & 0.094 & & $0(0 \%)$ \\
\hline & Nitrofurantoin & $3 \ldots 96$ & 6 & & $3(43 \%)$ \\
\hline & Norfloxacin & $0.19 \ldots 1.5$ & 0.38 & & $0(0 \%)$ \\
\hline & Clindamycin & $0.1 \ldots 4$ & 1.5 & & $6(86 \%)$ \\
\hline \multirow{8}{*}{ C. striatum (4) } & TMP/SMX & $0.094 \ldots 0.5$ & & & $0(0 \%)$ \\
\hline & Doxycycline & $0.064 \ldots 0.38$ & & & $0(0 \%)$ \\
\hline & Erythromycin & $<0.016 \ldots 3$ & & & $1(25 \%)$ \\
\hline & Penicillin G & $0.016 \ldots 0.38$ & & & $0(0 \%)$ \\
\hline & Ampicillin-sulbactam & $0.023 \ldots 0.38$ & & & $0(0 \%)$ \\
\hline & Nitrofurantoin & $24 \ldots>512$ & & & $2(50 \%)$ \\
\hline & Norfloxacin & $0.25 \ldots 0.38$ & & & $0(0 \%)$ \\
\hline & Clindamycin & $0.004 \ldots 3$ & & & $2(50 \%)$ \\
\hline \multirow{8}{*}{ Corynebacterium group F 1 (2) } & TMP/SMX & $0.125 \ldots 3$ & & & $1(50 \%)$ \\
\hline & Doxycycline & $4 \ldots 24$ & & & $1(50 \%)$ \\
\hline & Erythromycin & $1.5 \ldots>256$ & & & $2(100 \%)$ \\
\hline & Penicillin G & $0.094 \ldots 0.125$ & & & $0(0 \%)$ \\
\hline & Ampicillin-sulbactam & $0.125 \ldots 0.125$ & & & $0(0 \%)$ \\
\hline & Nitrofurantoin & $48 \ldots 48$ & & & $2(100 \%)$ \\
\hline & Norfloxacin & $0.5 \ldots 12$ & & & $1(50 \%)$ \\
\hline & Clindamycin & $>256 \ldots>256$ & & & $2(100 \%)$ \\
\hline
\end{tabular}


(Table 1) contd......

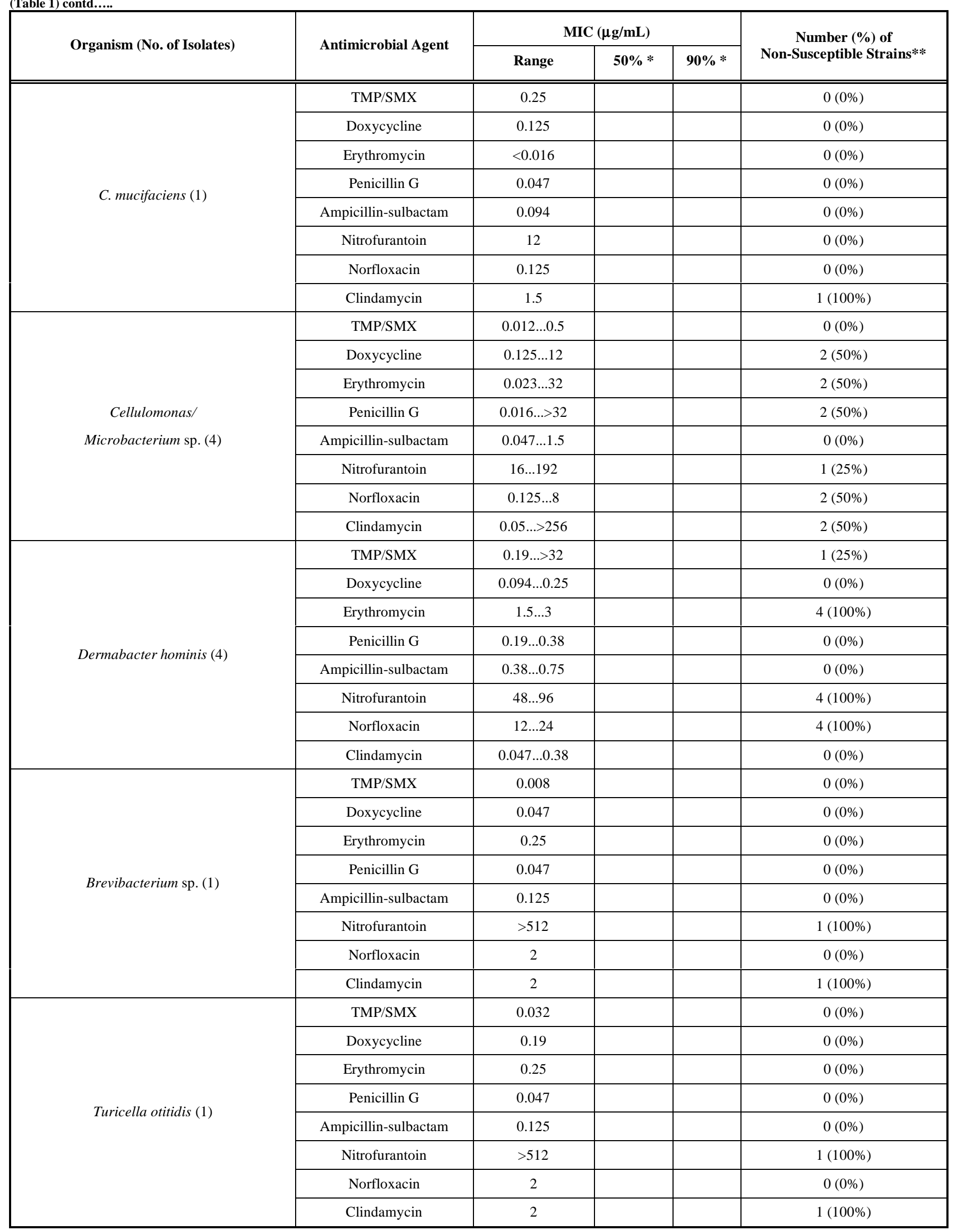


(Table 1) contd.....

\begin{tabular}{|c|c|c|c|c|c|}
\hline \multirow{2}{*}{ Organism (No. of Isolates) } & \multirow{2}{*}{ Antimicrobial Agent } & \multicolumn{3}{|c|}{$\mathrm{MIC}(\mu \mathrm{g} / \mathrm{mL})$} & \multirow{2}{*}{$\begin{array}{c}\text { Number }(\%) \text { of } \\
\text { Non-Susceptible Strains }\end{array}$} \\
\hline & & Range & $\mathbf{5 0 \%} *$ & $90 \% *$ & \\
\hline \multirow{8}{*}{ Arthrobacter sp. (1) } & TMP/SMX & 1 & & & $0(0 \%)$ \\
\hline & Doxycycline & 0.75 & & & $0(0 \%)$ \\
\hline & Erythromycin & 0.047 & & & $0(0 \%)$ \\
\hline & Penicillin G & 0.094 & & & $0(0 \%)$ \\
\hline & Ampicillin-sulbactam & 0.25 & & & $0(0 \%)$ \\
\hline & Nitrofurantoin & $>512$ & & & $1(100 \%)$ \\
\hline & Norfloxacin & 4 & & & $0(0 \%)$ \\
\hline & Clindamycin & 0.75 & & & $1(100 \%)$ \\
\hline
\end{tabular}

* $50 \%$ and $90 \%$ stand for MIC50 and MIC 90 , respectively.

** Non-susceptible strains include resistant and intermediate strains. Since ampicillin-sulbactam, nitrofurantoin and norfloxacin are not represented in the CLSI interpretive criteria entry for Corynebacterium sp., the interpretive criteria for Staphylococcus sp. have been used for those three antimicrobial agents, instead.

*** TMP/SMX: trimethoprim-sulfamethoxazole

ganism was often resistant to norfloxacin that is commonly used for treatment of male genital tract infections. Since treatment of prostatitis usually does not aim for a particular target, susceptibility of possible pathogens may give valuable information for choosing an antibiotic.

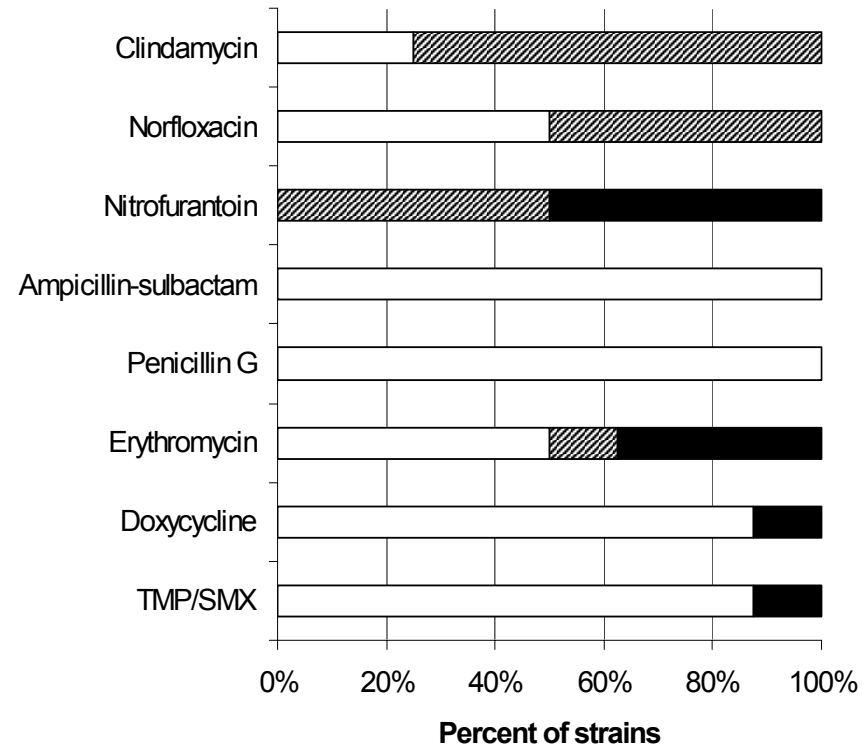

Fig. (1). Susceptibility pattern of Corynebacterium group G. White - susceptible; striped - intermediate; black - resistant.

Our resistance data principally agreed with the previous data, although there exists more information about invasive than mucosal strains. According to a rule of the thumb, mucosal strains are usually more susceptible than the invasive ones but there are exceptions like pneumococci [13]. In general, the susceptibility patterns of coryneform bacteria seem to be poorly predictable.

Fluoroquinolones are suggested as cost-effective and safe drugs. At the same time, $C$. amycolatum and $C$. striatum can serve as examples of species against which the activity of fluoroquinolones has rapidly decreased [14]. In our study, $C$. jeikeium, $C$. striatum and majority of the $C$. seminale strains were susceptible to norfloxacin. Although bimodal spread of susceptibility (MIC either $<0.5$ or $>4 \mu \mathrm{g} / \mathrm{mL}$ ) to ciprofloxacin has been described [15], similar pattern did not appear in our study.

Resistance to beta-lactam antimicrobials among the coryneforms varies, $C$. seminale, $T$. otitidis and Arthrobacter sp. have been shown to be more susceptible to penicillin $G$ than $C$. jeikeium, $C$. striatum, and D. hominis [7, 12, 16, 17]. Our strains were highly susceptible, except Cellulomonas/Microbacterium group.

Our data corresponds to several studies that have shown high resistance of coryneforms to macrolides and lincosamines $[6,7,15,17,18]$ and there is a distinct resistance pattern, MLSb (a co-occurring resistance to Macrolide, Lincosamine and Streptogramin B) [8]. In our study, 16 strains (13 C. seminale, 2 Cellulomonas/Microbacterium $\mathrm{sp}$. and 1 Corynebacterium group F1) showed concurrent resistance to erythromycin and clindamycin.

Unlike earlier studies [6,8], in our study, C. jeikeium and C. seminale did not have low MICs of nitrofurantoin. Another discord with earlier reports was revealed in case of TMP/SMX that was highly active on the majority of the strains studied by us while weak or missing activity of it against $C$. striatum, $C$. jeikeium, D. hominis and $T$. otitidis has been described [18-20]. Our results justify the role of TMP/SMX as the drug of choice for prostatitis in Canada [21].

Resistance to tetracyclines among corynebacteria is controversial - generally multiresistant species like $C$. jeikeium and $C$. amycolatum are relatively susceptible, while $C$. seminale and $C$. striatum quite resistant $[7,18]$. D. hominis, $T$. otididis [20] and Cellulomonas sp. [7] have been susceptible. With that, our data generally agreed, except that our $C$. striatum strains were susceptible to doxycycline.

In conclusion, ampicillin-sulbactam, penicillin $G$ and TMP/SMX revealed the highest activity against coryneforms isolated from semen that were frequently resistant or intermediate to several other antimicrobials. Norfloxacin revealed only moderate activity against prostatitis-associated Corynebacterium group $\mathrm{G}$. 


\section{ACKNOWLEDGEMENTS}

The authors would like to thank Dr. Kristo Ausmees, Dr. Paul Korrovits and Dr. Krista Lõivukene for excellent technical help. The study was supported by the Estonian Science Foundation (grant No. 5701), Commission of the European Union (grant No. QLRT-2001-02911), and Estonian Ministry of Education and Research (target financing No. SF0180132s08).

\section{REFERENCES}

[1] Türk S, Korrovits P, Punab M, Mändar R. Coryneform bacteria in semen of chronic prostatitis patients. Int J Androl 2007; 30: 123-8.

[2] Domingue GJ, Hellstrom WJG. Prostatitis. Clin Microbiol Rev 1998; 11: 604-13.

[3] Tanner MA, Shoskes D, Shahed A, Pace NR. Prevalence of corynebacterial 16S rRNA sequences in patients with bacterial and "nonbacterial" prostatitis. J Clin Microbiol 1999; 37: 1863-70.

[4] Riegel P, Ruimy R, de Briel D, et al. Corynebacterium seminale sp. nov., a new species associated with genital infections in male patients. J Clin Microbiol 1995; 33: 2244-9.

[5] Otsuka Y, Kawamura Y, Koyama T, Iihara H, Ohkusu K, Ezaki T. Corynebacterium resistens $\mathrm{sp}$. nov., a new multidrug-resistant coryneform bacterium isolated from human infections. J Clin Microbiol 2005; 43: 3713-7.

[6] Soriano F, Zapardiel J, Nieto E. Antimicrobial susceptibilities of Corynebacterium species and other non- spore-forming grampositive bacilli to 18 antimicrobial agents. Antimicrob Agents Chemother 1995; 39: 208-14.

[7] Funke G, von Graevenitz A, Clarridge JE 3rd, Bernard KA. Clinical microbiology of coryneform bacteria. Clin Microbiol Rev 1997; 10: $125-59$.

[8] Rosato AE, Lee BS, Nash KA. Inducible macrolide resistance in Corynebacterium jeikeium. Antimicrob Agents Chemother 2001; 45: 1982-9.

[9] Isenberg HD: Clinical Microbiology Procedures Handbook. ASM Press, Washington, 2004
[10] Clinical and Laboratory Standards Institute. Methods for Antimicrobial Dilution and Disk Susceptibility Testing of Infrequently Isolated or Fastidious Bacteria; Approved Guideline, CLSI document M45-A. CLSI, Wayne, PA, 2006.

[11] Clinical and Laboratory Standards Institute. Performance Standards for Antimicrobial Susceptibility Testing; Fifteenth Informational Supplement M2-A8 and M7-A6. CLSI, Wayne, PA, 2005.

[12] Funke G, Pünter V, von Graevenitz A. Antimicrobial susceptibility patterns of some recently established coryneform bacteria. Antimicrob Agents Chemother 1996; 40: 2874-8.

[13] Lehmann D, Gratten M, Montgomery J. Susceptibility of pneumococcal carriage isolates to penicillin provides a conservative estimate of susceptibility of invasive pneumococci. Pediatr Infect Dis J 1997; 16: 297-305.

[14] Sierra JM, Martinez-Martinez L, Vázquez F, Giralt E, Vila J. Relationship between mutations in the gyrA gene and quinolone resistance in clinical isolates of Corynebacterium striatum and Corynebacterium amycolatum. Antimicrob Agents Chemother 2005; 49: 1714-9.

[15] Fernandez EP, Vela AI, Las Heras A, Dominguez L, FernandezGarayzabal JF, Moreno MA. Antimicrobial Susceptibility of corynebacteria isolated from ewes mastitis. Int J Antimicrob Agents 2001; 18: 571-4.

[16] Radtke A, Bergh K, Øien CM, Bevanger LS. Peritoneal dialysisassociated peritonitis caused by Dermabacter hominis. J Clin Microbiol 2001; 39: 3420-1.

[17] Ubaldi M, D’Annibale ML, Medori MC, Crotti D. Coryneform Bacteria: their clinical significance and resistance patterns during a three-year study. Infez Med 2004; 12: 126-31.

[18] Martinez-Martinez L, Pascual A, Bernard K, Suarez AI. Antimicrobial susceptibility pattern of Corynebacterium striatum. Antimicrob Agents Chemother 1996; 40: 2671-2.

[19] Traub WH, Geipel U, Leonhard B, Bauer D. Antibiotic susceptibility testing (agar disk diffusion and agar dilution) of clinical isolates of Corynebacterium jeikeium. Chemotherapy 1998; 44: 230-7.

[20] Troxler R, Funke G, Von Graevenitz A, Stock I. Natural antibiotic susceptibility of recently established coryneform bacteria. Eur J Clin Microbiol Infect Dis 2001; 20: 315-23.

[21] Nickel JC, Nigro M, Valiquette L, et al. Diagnosis and treatment of prostatitis in Canada. Urology 1998; 52: 797-802.

(c) Türk et al.; Licensee Bentham Open.

This is an open access article licensed under the terms of the Creative Commons Attribution Non-Commercial License (http://creativecommons.org/licenses/by$\mathrm{nc} / 3.0 /$ ) which permits unrestricted, non-commercial use, distribution and reproduction in any medium, provided the work is properly cited. 